\title{
DRIVERS' EYE GLANCE TRANSITIONS AND THE IMPLICATIONS ON THE MICROSCOPIC TRAFFIC AND ACCIDENT SIMULATION
}

\author{
YEEUN KIM, SEHYUN TAK, SEONGJIN CHOI \& HWASOO YEO \\ Department of Civil and Environmental Engineering, KAIST, South Korea
}

\begin{abstract}
Driver's inattention and distraction are one of the main causes of traffic accidents. Therefore, understanding on the driver's behavior of inattention and distraction gives important implications for improving traffic safety. Previous researches tried to identify the main factors leading to accidents and their impact on traffic accidents. However, it is hard to model and estimate the impact as the drivers' distraction shows stochastic transitions. In this study, we try to provide a better understanding on the relationship between distraction and vehicle safety and analyze the dynamics of driver vision transitions in both normal driving situation and accident situation. Based on the result, we propose a new car-following model, which can reflect the driver's dynamic vision transition, which can regenerate the risk situations that the existing car-following models cannot provide. The new model can provide a framework for better understanding on the relationship of traffic accidents and drivers vision transition.

Keywords: vision transition, distraction, naturalistic driving, driver's distraction based car-following model.
\end{abstract}

\section{INTRODUCTION}

Car accidents are caused by different reasons related to the driver's behavior such as driver's perception reaction time and aggressiveness. Especially, driver distraction has been proven as one of the most critical causal factors of traffic accidents [1]-[4].

In the earlier days of researches on driver distraction and inattention, people focused mainly on illuminating distraction factors causing traffic accidents [5]-[7]. They considered secondary tasks such as using cell-phone or manipulating in-vehicle devices as a main cause of driver's distraction. However, these studies have not taken into account the mechanism of how distraction leads to accidents. With the development of more in-vehicle devices, these secondary tasks have become the common behavior of concern. In order to prevent accident effectively, it is necessary to investigate the distraction leading to accidents.

Some researchers have focused on driver's visual behavior to determine driver distraction [8], [9]. Many studies have analyzed the relationship between driver's distraction and accident risk quantitatively. Kircher considered the off-road glance to be a major factor [10]. Kircher and Ahlström have analyzed off-road glance duration [11] and Donmez et al., used clustering method using off-road glance duration and frequency [12]. Although these studies present useful results, they did not consider the distraction that occurs in on-road glance. For example, even though driver is looking at the road, looking at the side for a long time can be considered as a distraction causing accidents.

Moreover, some researchers have tried to identify visual attention allocation to better understand drivers' driving characteristics. Some studies represented the process of driver's visual attention allocation as a probability of gazing focal point [13]-[15]. In order these 
limitations, Wong and Huang analyzed the driver's vision transition through attention allocation pattern analysis and multinomial choice model [16], [17].

In order to use these results in practice, such as considering it for new system development, it should be able to reproduce how it happens in various situations. Traffic simulation is being used as a good alternative to overcome the difficulty of performing on-road experiment. Previous researches have limitations in terms of applications as they cannot describe microscopic behavior.

Therefore, this study mainly aims two purposes. First, driving characteristics in various driving environment will be analyzed under normal driving situation and event situation. Then, based on these results, new car-following model that can describe accident situation will be proposed by adopting driver's vision transition. This will help overcome the limitations of the existing car-following model and extend the usage of the car-following models to the accidents situations.

\section{DRIVER EYE GLANCE TRANSITION ANALYSIS}

The goal of this study is figuring out driving characteristics in various environment and development of new car-following model. In this chapter, driving characteristics will be understood through driver's eye glance transition analysis. Eye glance data from the VTTI 100 -car naturalistic driving study was analyzed using Markov dynamic model.

\subsection{0-car NDS data}

This study used the 100-car Naturalistic Driving Study (NDS) data developed by a research project of Second Strategic Highway Research Program (SHRP2) which is supported and operated by the Virginia Tech Transportation Institute (VTTI) [18]. The released online data includes two types of database, a baseline and an event. The baseline database which describes normal driving situation contains 4803 data, and the event database consists of 68 crashes and 760 near-crashes.

Both databases are composed of eye glance data and video reduced data. Eye glance data is the time series data that records the glance location and the duration, and video reduced data includes various attributes of driver and road environment during the driving such as driver's gender, traffic density, relation to junction, and weather. In the case of eye glance data, the recorded time is different for both databases. Baseline data recorded 6.1 seconds at 0.1 second intervals, and event data recorded 30 seconds data including 20 seconds before and 10 seconds after an impact.

\subsection{Markov dynamic model}

It is important to understand sequential characteristics of eye glance behavior in various situations due to the characteristics of this study, which aims to analyze drivers' eye glance behavior in various driving environments and apply them to car-following models. Markov model is commonly used for modeling and prediction of human behaviors such as speech, gestures and vision with its characteristic that can consider sequential movement [19]. In this study, therefore, Markov chain will be used to analyze driver's vision transition probability.

\subsubsection{Markov transition model}

Discrete-time Markov transition model is used to measure the transition probabilities of several categorized glance locations. Maximum likelihood estimation method is adapted for using Markov model to estimate driver vision transition. In case of accident situations including crash and near-crash, 6.1 seconds right before the event start is used as baseline 
data includes only 6.1 seconds time series data. In addition, to prevent overestimation of keeping eye glance in same location, data is aggregated in one second time step under stationary Markov process.

\subsubsection{Glance state}

Previous researches have usually considered eye glance location into two groups, such as forward/non-forward or on-road/off-road. However, this category cannot describe visual characteristics in various road conditions. For example, in case of intersection, drivers need to pay more attention on left and right side compared to highway where looking forward is dominant visual behavior. Considering this fact, some studies attempted to classify the eye glances as five (forward, left, right, rear view, in-vehicle) [16], [17]. However, these five categories were not suitable for Markov chain analysis because of the similar situational characteristics with frequent left and right-looking and low frequency of right-looking. From this point of view, 14 glance locations are classified into four groups in order to more clearly represent the Markov chain: forward, rear view, side, and off-road. Off-road includes invehicle devices manipulations and abnormal eyes closed situation.

\subsubsection{Various road environment}

Video reduced data contains several attributes describing driving environment. They can be classified into two groups, driver characteristics and road environment. In this study, relation to junction and traffic density information were used in road environment. According to attributes, both baseline data and event data were divided into several groups which show similar eye glance patterns.

For relation to junction, data were classified in three groups, non-junction, intersection, and intersection-related. Traffic density, which was originally classified as LOS A to F, was classified as stable and unstable. Stable includes relatively good traffic conditions from LOS A to D, and unstable including LOS E and F represents congestion situation. Meanwhile, to analyze the effect of traffic density, only non-junction data is used to minimize the impact of other factors. Sample size of data following each attribute can be found in Table 1 .

\subsubsection{Cumulative distribution of eye glance duration}

The driver vision transition matrix obtained in the Markov chain can be used to describe the driver's visual behavior. However, this method rarely causes the problem that the visual allocation of the driver stays only in one state. In particular, when the driver maintains a gaze at a non-forward location, the model presents a very unrealistic result. To prevent this problem, cumulative distribution of eye glance duration is additionally analyzed. This allows maximum duration of gazing at each location to be determined and can be used for force termination of gazing when it continues too long.

Table 1: Sample size according to attributes.

\begin{tabular}{|c|c|c|c|}
\hline \multicolumn{2}{|c|}{ Attributes } & \multicolumn{2}{c|}{ Sample size } \\
\cline { 3 - 4 } & & Baseline & Event \\
\hline \multirow{2}{*}{ Relations to } & Non-junction & 4015 & 413 \\
junction & Intersection & 296 & 134 \\
& Intersection-related & 246 & 70 \\
\hline \multirow{2}{*}{ Density } & Stable & 3959 & 390 \\
& Unstable & 56 & 23 \\
\hline
\end{tabular}




\subsection{Results}

In total, 4557 baseline data and 617 event data were used to analyze driver's visual behavior. Driver's vision transition and cumulative distribution of eye glance duration are analyzed according to various relation to junction and traffic density. Glance locations are classified in four groups, forward $(\mathrm{F})$, side $(\mathrm{S})$, rear view $(\mathrm{R})$, and off-road $(\mathrm{O})$.

\subsubsection{Relation to junction}

Table 2 shows the vision transition matrix of normal driving and accident situation according to relation to junction. In most situation, looking forward $(F)$ is the most dominant behavior of drivers. The probability of returning from the other state to $F$ is significantly higher than the probability of transition between two both states, and the probability of return is also highest in F. In normal driving situation at non-junction, driver stares at F mainly, and the regression probability of $\mathrm{S}$, which occurs mostly in lane changing, is about 0.33 . The regression probability of $\mathrm{O}$ is 0.29 , which is slightly lower than that, and 0.1 is the lowest for R. At the intersection, there are quite different characteristics for S. The probability of transition from others to $\mathrm{S}$ is slightly increased, and the regression probability of $\mathrm{S}$ is over 0.5 , which is much higher than that of non-junction. At intersection-related, regression probability of $\mathrm{R}, \mathrm{S}$, and $\mathrm{O}$ increased. At intersection-related, drivers show intermediate characteristics in non-junction and intersection for the probability of transition to $\mathrm{F}$ and $\mathrm{S}$ and for each regression probability. On the other hand, the regression probability of $\mathrm{O}$ is very high, which is considered to be due to the frequent signal waiting situations considering intersection-related road characteristics.

In accident situation, driver's visual behavior is significantly different. First of all, regardless of the type of relation to junction, the probability of returning to $\mathrm{O}$, including the regression probability, is generally high. This is consistent with the results of previous studies in which distraction is a major component of accident, as the time for the driver to maintain $\mathrm{O}$ is long. Not only for $\mathrm{O}$, but all four locations show higher regression probability which means longer glance duration.

Fig. 1 shows cumulated distribution of four eye glance locations. The slope of the graph shows how quickly the behavior of looking at each point are terminated. As shown in the transition matrix, in accident situation, the slope of the graph is gentler than in normal driving situations. The slope of the graph according to the location tends to become gentle in the order of S, O, R and F, though there is slight difference in each case.

Table 2: Eye glance transition matrix according to relation to junction.

\begin{tabular}{|c|c|c|c|c|c|c|c|c|c|}
\hline & & \multicolumn{4}{|c|}{ Normal } & \multicolumn{4}{|c|}{ Accident } \\
\hline & & $\mathrm{R}$ & $\mathrm{F}$ & $\mathrm{O}$ & $\mathrm{S}$ & $\mathrm{R}$ & $\mathrm{F}$ & $\mathrm{O}$ & $\mathrm{S}$ \\
\hline \multirow{4}{*}{ Non-junction } & $\mathrm{R}$ & 0.113 & 0.821 & 0.022 & 0.083 & 0.418 & 0.513 & 0 & 0.047 \\
\hline & $\mathrm{F}$ & 0.027 & 0.878 & 0.035 & 0.058 & 0.021 & 0.881 & 0.036 & 0.057 \\
\hline & $\mathrm{O}$ & 0.019 & 0.654 & 0.291 & 0.035 & 0 & 0.54 & 0.5 & 0.025 \\
\hline & $\mathrm{S}$ & 0.035 & 0.627 & 0.011 & 0.337 & 0.027 & 0.659 & 0.022 & 0.305 \\
\hline \multirow{4}{*}{ Inter-section } & $\mathrm{R}$ & 0.599 & 1.009 & 0.026 & 0.07 & 0.077 & 0.558 & 0.082 & 0.094 \\
\hline & $\mathrm{F}$ & 0.032 & 0.82 & 0.04 & 0.106 & 0.017 & 0.909 & 0.025 & 0.06 \\
\hline & $\mathrm{O}$ & 0 & 0.644 & 0.27 & 0.057 & 0 & 0.491 & 0.367 & 0 \\
\hline & $\mathrm{S}$ & 0.015 & 0.418 & 0.016 & 0.538 & 0.009 & 0.342 & 0.03 & 0.621 \\
\hline \multirow{4}{*}{$\begin{array}{l}\text { Inter-section- } \\
\text { related }\end{array}$} & $\mathrm{R}$ & 0.172 & 0.65 & 0.032 & 0.173 & 0.5 & 0.2 & 0 & 0 \\
\hline & $\mathrm{F}$ & 0.027 & 0.849 & 0.024 & 0.088 & 0.009 & 0.905 & 0.034 & 0.046 \\
\hline & $\mathrm{O}$ & 0 & 0.518 & 0.479 & 0.067 & 0 & 0.449 & 0.64 & 0 \\
\hline & $\mathrm{S}$ & 0 & 0.523 & 0.011 & 0.509 & 0 & 0.39 & 0 & 0.639 \\
\hline
\end{tabular}




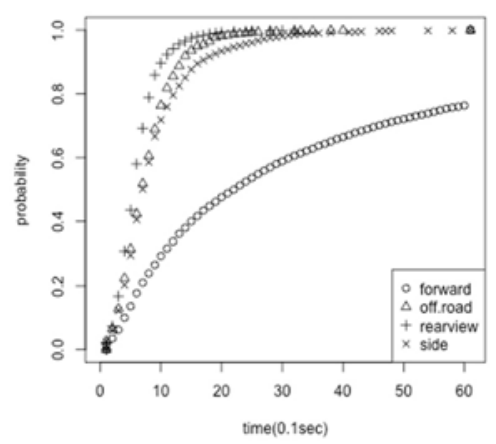

(a) Normal driving, non-junction

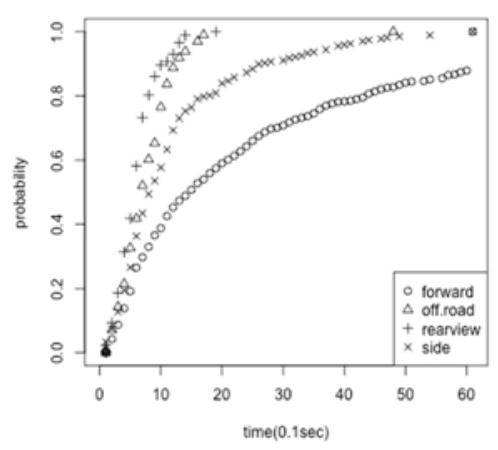

(c) Normal driving, intersection

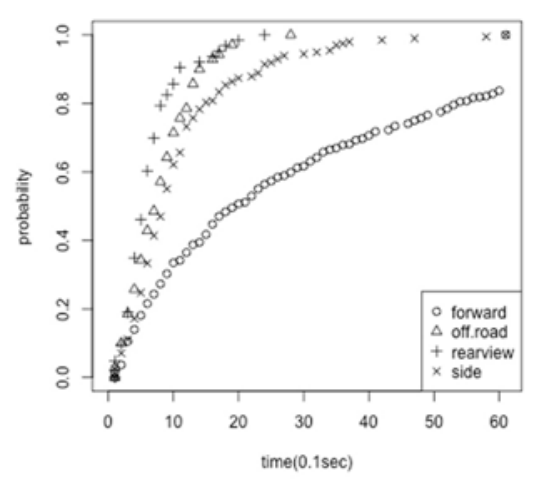

(e) Normal driving, intersectionrelated

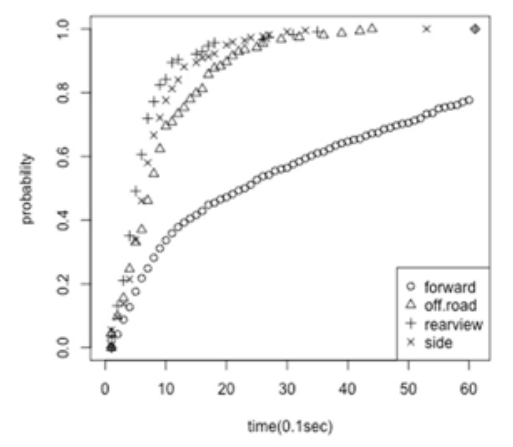

(b) Accident situation, non-junction

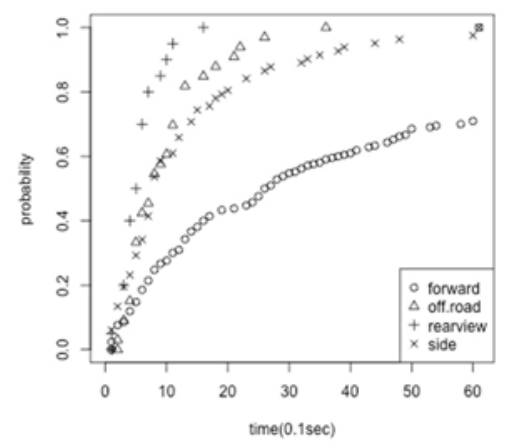

(d) Accident situation, intersection

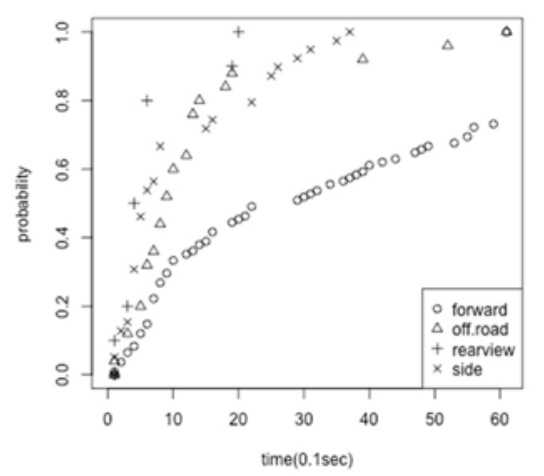

(f) Accident situation, intersectionrelated

Figure 1: Cumulated distribution function of glance location states by relation to junction.

\subsubsection{Traffic density}

We analyze the driving characteristics according to traffic density for driving at non-junction. Thus, the result of a situation in which the traffic density is stable represents the driver's eye glance behavior in the most ideal situation. In this case, the vision transition is similar to the 
result of the non-junction and normal driving situation case discussed in Section 2.3.1. Compare to this, when traffic density is unstable, the probability of transition to F decreased and the regression probability of $\mathrm{O}, \mathrm{R}$, and $\mathrm{S}$ increased noticeably. The disappearance of the transition from $\mathrm{R}$ to other non-forward locations is also a noteworthy feature.

In the case of an accident, the transition matrix showed a pattern similar to that of normal driving in an unstable state. When unstable, that is, when there is congestion, it can be nature that the behavior of watching non-forward is prominent because the average speed is usually slow and the car is stopped frequently. However, similar behavior in a stable situation implies driver's distraction. In an unstable state, this gets even worse. In addition, there are many cases where the transition probability become zero compared to other cases, so it can be judged that the driving behavior is more naïve.

In the relation to junction classification, the slope of each location was different, but the slope order was kept constant, whereas the change of traffic density affected the slope order of non-forward glance locations. According to Fig. 2, while the slope of F is similar in all cases, in other non-forward locations, the slopes vary from case to case. This suggests that the traffic density has a significant effect on the driving characteristics.

\section{NEW CAR-FOLLOWING MODEL CONSIDERING DRIVER VISION TRANSITION}

\subsection{Development of car-following model considering driver vision transition}

To simulate unsafe situations caused by driver vision transition and perception error, we developed a car-following model with Markov dynamic model presented in previous sections. The basic assumption made in this study is that, when the glance state of driver is "forward", the movement of subject vehicle follows normal car-following model since they observe and make decisions on their longitudinal movements. Otherwise, when the glance state of driver is non-forward state, the driver keeps the acceleration in previous decision, which called inattention car-following model in this paper.

Table 3: Eye glance transition matrix according to traffic density.

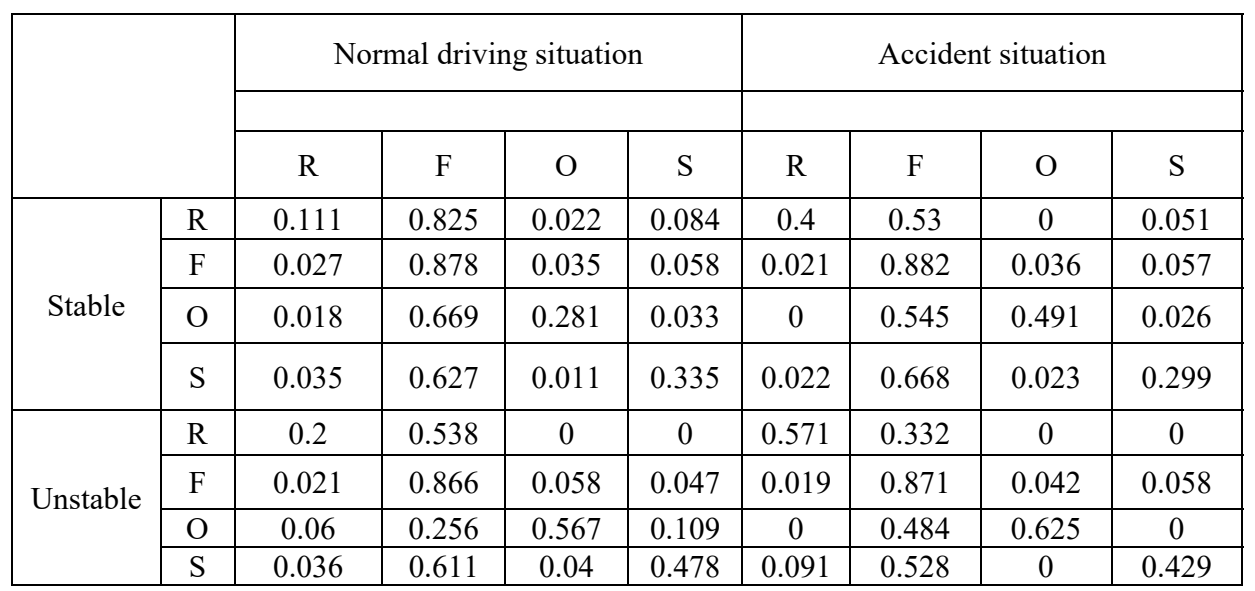




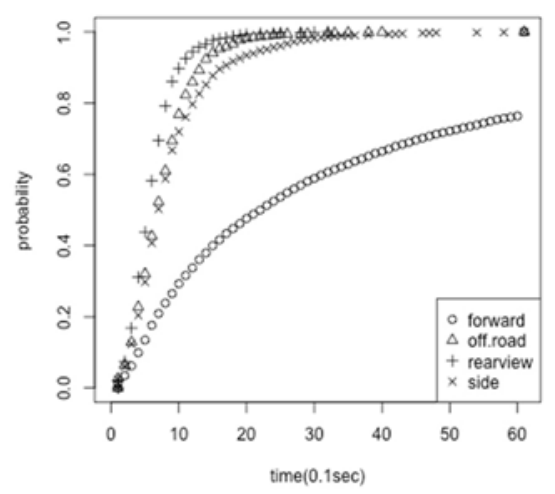

(a) Normal driving, stable

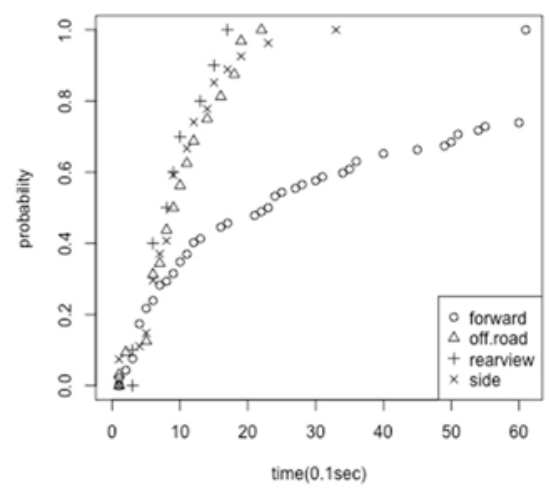

(c) Normal driving, unstable

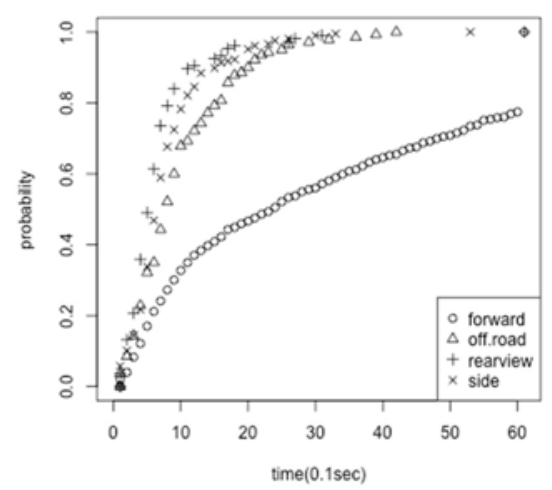

(b) Accident situation, stable

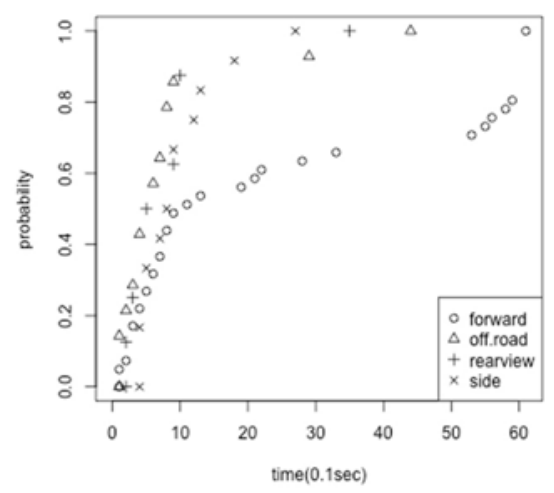

(d) Accident situation, unstable

Figure 2: Cumulated distribution function of glance location states by traffic density.

To formulate this behavior, at a given time $t$, if the glance state of vehicle $n$ is given as $S_{n}(t)$, the normal car-following model is expressed as follows:

$$
x_{n}(t+\Delta t)=\left\{\begin{array}{cc}
x_{n}^{\text {normal }}(t+\Delta t), & \text { if } S_{n}(t+\Delta t)=\text { "forward" } \\
x_{n}^{\text {inattention }}(t+\Delta t) & \text {, otherwise }
\end{array}\right.
$$

At time $t$ if glance state is given as $i$ and the glance duration is given as $d$, the glance state at next time step can be defined with a random number ( $\operatorname{rand}(1))$ between 0 and 1 as shown below.

$$
S_{n}(t+\Delta t)=\left\{\begin{array}{c}
\text { "forward" }, \text { if } \Sigma_{j}^{\{\text {forward }\}} p_{i \rightarrow j}(d) \geq \operatorname{rand}(1) \\
\text { "side" }, \text { else if } \Sigma_{j}^{\{\text {forward,side }\}} p_{i \rightarrow j}(d) \geq \operatorname{rand}(1) \\
\text { "rearview" }, \text { else if } \Sigma_{j}^{\{\text {forward,side,rearview }\}} p_{i \rightarrow j}(d) \geq \operatorname{rand}(1) \\
\text { "off }- \text { road" , otherwise }
\end{array}\right.
$$


If the glance state at time $t+\Delta t$ is decided, based on the glance state, the car-following model is decided either to follow inattention car-following model or to follow normal car-following model as shown in eqn (1).

The inattention car-following model is shown below:

$$
\mathrm{x}_{\mathrm{n}}^{\text {off-road }}(\mathrm{t}+\Delta \mathrm{t})=\max \left(\mathrm{x}_{\mathrm{n}}(\mathrm{t}), \mathrm{x}_{\mathrm{n}}(\mathrm{t})+\mathrm{v}_{\mathrm{n}}(\mathrm{t}) \Delta \mathrm{t}+\mathrm{a}_{\mathrm{n}}(\mathrm{t}) \Delta \mathrm{t}^{2}\right)
$$

The normal car-following model is based on the modified car-following model in Oversaturated Freeway Flow Algorithm (OFFA) [20], [21]. The car-following model is shown below.

$$
\mathrm{x}_{\mathrm{n}}^{\text {normal }}(\mathrm{t}+\Delta \mathrm{t})=\min \left(\mathrm{x}_{\mathrm{n}}^{\mathrm{U}}(\mathrm{t}+\Delta \mathrm{t}), \mathrm{x}_{\mathrm{n}}^{\mathrm{L}}(\mathrm{t}+\Delta \mathrm{t})\right)
$$

The upper boundary $\left(\mathrm{x}_{\mathrm{n}}^{\mathrm{U}}(\mathrm{t}+\Delta \mathrm{t})\right)$ for updated location is:

$$
x_{n}^{U}(t+\Delta t)=\min \left\{\begin{array}{c}
x_{n-1}(t)-v_{n-1}(t) \cdot \tau_{n}-s_{n}^{j a m} \\
x_{n}(t)+v_{n}(t) \Delta t+a_{n} \Delta t^{2}, \\
x_{n}(t)+v_{n}^{f} \cdot \Delta t \\
x_{n}(t)+\Delta x_{n}^{s}(t)
\end{array}\right\},
$$

where $x_{n}(t)$ is position of vehicle $n$ at time $t, v_{n}(t)$ is the speed of vehicle $n$ at time $t, \tau_{n}$ is reaction time of vehicle $n, s_{n}^{j a m}$ is jam spacing of vehicle $n, v_{n}^{f}$ is free flow speed of vehicle $n, a_{n}$ is maximum acceleration rate of vehicle $n$, and $b_{n}$ is maximum deceleration rate of vehicle $n$.

$$
\begin{gathered}
\Delta x_{n}^{s}(t)=\Delta t\left(b_{n} \tau_{n}+\sqrt{\left(b_{n} \tau_{n}\right)^{2}-2 b_{n}\left(x_{n-1}(t)-x_{n}(t)-s_{n}^{j a m}+d_{n-1}(t)\right)}\right) \\
d_{n-1}(t)=-\frac{\left(v_{n-1}(t)\right)^{2}}{2 b_{n-1}}
\end{gathered}
$$

The lower boundary $\left(\mathrm{x}_{\mathrm{n}}^{\mathrm{L}}(\mathrm{t}+\Delta \mathrm{t})\right)$ for updated location is:

$$
\mathrm{x}_{\mathrm{n}}^{\mathrm{L}}(\mathrm{t}+\Delta \mathrm{t})=\max \left\{\mathrm{x}_{\mathrm{n}}(\mathrm{t})+\mathrm{v}_{\mathrm{n}}(\mathrm{t}) \Delta \mathrm{t}+\mathrm{b}_{\mathrm{n}} \Delta \mathrm{t}^{2}, \mathrm{x}_{\mathrm{n}}(\mathrm{t})\right\}
$$

Also, perception error term is applied to position and speed of leader vehicle and speed of subject vehicle with given standard deviations as shown in following equations.

$$
\begin{gathered}
\mathrm{x}_{\mathrm{n}-1}=\mathrm{x}_{\mathrm{n}-1}+\epsilon_{\mathrm{x}} \text {, where } \epsilon_{\mathrm{x}} \sim \mathrm{N}\left(0,\left|\mathrm{x}_{\mathrm{n}-1}-\mathrm{x}_{\mathrm{n}}\right| \cdot \lambda_{\mathrm{x}}\right) \\
\mathrm{v}_{\mathrm{n}-1}=\mathrm{v}_{\mathrm{n}-1}+\epsilon_{\mathrm{v}, \text { leader }} \text {, where } \epsilon_{\mathrm{v}, \text { leader }} \sim \mathrm{N}\left(0,\left|\mathrm{x}_{\mathrm{n}-1}-\mathrm{x}_{\mathrm{n}}\right| \cdot \lambda_{\mathrm{v}, \text { leader }}\right) \\
\mathrm{v}_{\mathrm{n}}=\mathrm{v}_{\mathrm{n}}+\epsilon_{\mathrm{v}, \text { subject }} \text {, where } \epsilon_{\mathrm{v}, \text { subject }} \sim \mathrm{N}\left(0, \lambda_{\mathrm{v}, \text { subject }}\right)
\end{gathered}
$$

\subsection{Simulation results}

Fig. 3 shows the effect on the eye glance behavior on the vehicle safety and car-following process with different cases: (a) normal driving situation, (b) dangerous driving situation, and (c) accident situation. In Fig. 3(a) which represents a normal driving situation, forwardlooking and non-forward looking behavior repeatedly occurred during a whole car following process. In this case, the eye glance behavior has not a significantly influence on the safety and driving actions such as acceleration and deceleration because a driver can keep an enough 
safety distance and a leader vehicle does not show any adverse action. However, a dangerous situation occurred when the leader vehicle reduces the speed with its maximum braking performance as illustrated in Fig. 3(b) and Fig. 3(c). In Fig. 3(b), the leader vehicle reduces speed near 30 seconds. The following vehicle detects this adverse action and reduces its speed appropriately because the driver in the following vehicle keeps attention to the movement of the preceding vehicle. In this case, the driver can avoid the accident. On the other hand, as in Fig. 3(c), the accident occurred due to the inattention of the driver of the following vehicle. In this case, the driver in the following vehicle does not look forward when the leader vehicle abruptly reduces the speed. As a result, the following vehicle crashes into the leader vehicle even though the following vehicle reduces the speed with its maximum braking performance after the following vehicle detects the leader vehicle's abrupt deceleration action.

(a) Normal driving situation

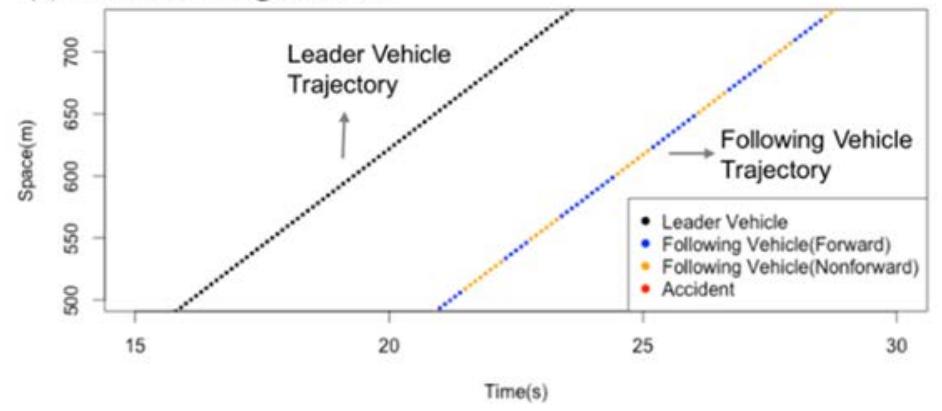

(b) Dangerous driving situation

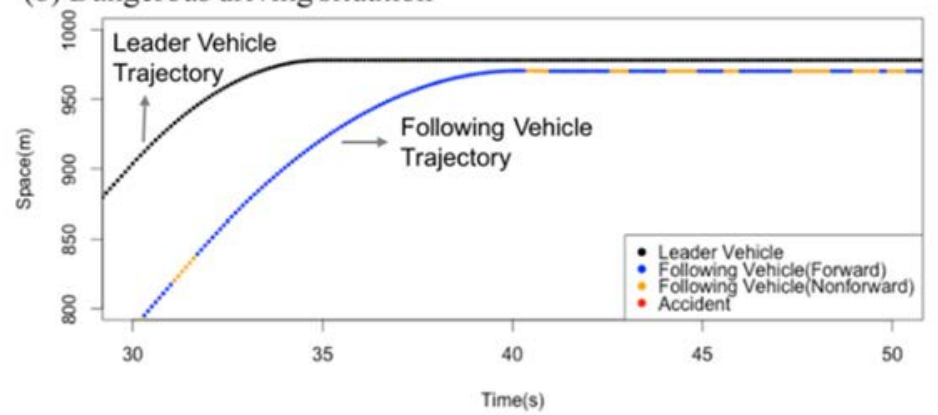

(c) Accident

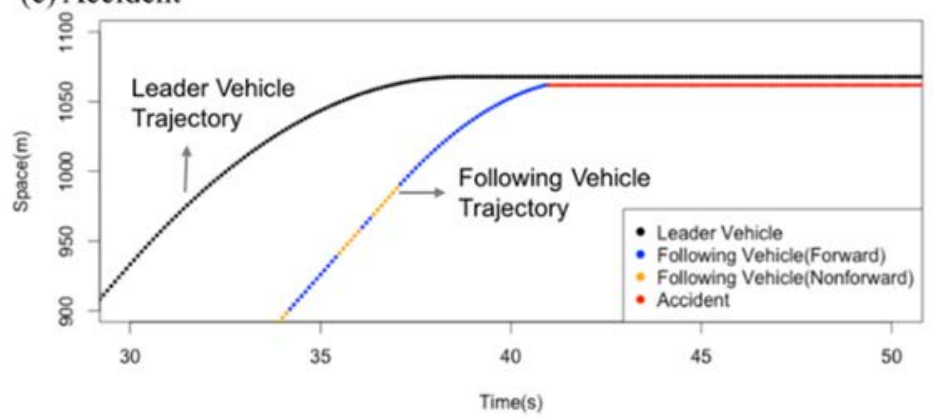

Figure 3: Simulation results. 


\section{CONCLUSION}

At first, in the analysis with state transition, we identify the transition matrix in various driving environments such as traffic density and relations to junction. The result shows that drivers have higher probability and duration of distraction and side-looking state at low LOS than high LOS. At the intersection and intersection-related region, the probability of side-looking shows significantly high and duration is also long. In addition, at the intersection, looking-forward duration is significantly shorter.

On the other hand, the main difference between normal driving situation and accident situation is the duration of the off-road state. The transition probability from forward-looking state to off-road state is not significantly different in both situations. But the duration of the off-road state is long in the accident situation compared to that of the normal driving situation. Meanwhile, at the intersection, there are distinctive differences from other situations. In this case, the significant difference between normal driving situation and accident situation is duration of forward-looking state. At the accident situation, drivers keeping their eye glance forward longer than that of normal driving situation.

Based on transition matrix for eye glance behavior, we proposed the new car-following model that can simulate the dangerous situation and an accident. As shown in the result, the proposed simulation can well represent the accident caused by the inattention behavior of driver.

\section{ACKNOWLEDGEMENTS}

This research was supported by a grant (17CTAP-C129888-01) from Technology Advancement Research Program (TARP) funded by Ministry of Land, Infrastructure, and Transport of Korean Government and a grant from ICT Promising Technology Development Support Program funded by MSIP (Ministry of Science, ICT and Future Planning) of Korean government and funded by the Ministry of Trade, Industry and Energy (MOTIE, KOREA) [Project ID: 10063147, Project Name: Multi-level safety system for intersection collision prevention].

\section{REFERENCES}

[1] Lee, J.D., Young, K.L. \& Regan, M.A., Defining driver distraction. Driver distraction: Theory, Effects, and Mitigation, 13(4), pp. 31-40, 2008.

[2] National Highway Traffic Safety Administration, National motor vehicle crash causation survey: Report to Congress, National Highway Traffic Safety Administration Technical Report DOT HS, 811, 059, 2008.

[3] Ascone, D., Lindsey, T. \& Varghese, C., Traffic safety factor: An examination of driver distraction as recorded in NHTSA databases, National Highway Traffic Safety Administration's National Center for Statistical and Analysis, 2009.

[4] National Highway Traffic Safety Administration. Blueprint for ending distracted driving, US Department of Transportation: Washington, DC, 2012.

[5] Horberry, T., Anderson, J., Regan, M.A., Triggs, T.J. \& Brown, J., Driver distraction: The effects of concurrent in-vehicle tasks, road environment complexity and age on driving performance. Accident Analysis and Prevention, 38(1), pp. 185-191, 2006.

[6] Stutts, J.C., Reinfurt, D.W., Staplin, L. \& Rodgman, E.A., The Role of Driver Distraction in Traffic Crashes, 2001.

[7] Klauer, S.G., Neale, V.L., Dingus, T.A., Ramsey, D. \& Sudweeks, J., Driver inattention: A contributing factor to crashes and near-crashes. In Proceedings of the Human Factors and Ergonomics Society Annual Meeting, 49(22), pp. 1922-1926). SAGE Publications: Sage CA, Los Angeles, 2005. 
[8] Blanco, M., Hankey, J.M. \& Chestnut, J.A., A taxonomy for secondary in-vehicle tasks based on eye glance and task completion time. In Proceedings of the human factors and ergonomics society annual meeting, 49(22), pp. 1975-1979). SAGE Publications: Sage CA: Los Angeles, 2005.

[9] Sodhi, M., Reimer, B. \& Llamazares, I., Glance analysis of driver eye movements to evaluate distraction. Behavior Research Methods, 34(4), pp. 529-538, 2002.

[10] Kircher, K. Driver distraction: A review of the literature. Statens väg-och transportforskningsinstitut, 2007.

[11] Kircher, K. \& Ahlström, C., Issues related to the driver distraction detection algorithm AttenD. In First International Conference on Driver Distraction and Inattention. Gothenburg, Sweden, 2009.

[12] Donmez, B., Boyle, L.N. \& Lee, J.D., Differences in off-road glances: effects on young drivers' performance. Journal of Transportation Engineering, 136(5), pp. 403-409, 2009.

[13] Wickens, C.D., Goh, J., Helleberg, J., Horrey, W.J. \& Talleur, D.A., Attentional models of multitask pilot performance using advanced display technology. Human Factors, 45(3), pp. 360-380, 2003.

[14] Horrey, W.J., Wickens, C.D. \& Consalus, K.P., Modeling drivers' visual attention allocation while interacting with in-vehicle technologies. Journal of Experimental Psychology: Applied, 12(2), p. 67, 2006.

[15] Wong, J.T. \& Huang, S.H., A microscopic driver attention allocation model. Advances in Transportation Studies an International Journal, pp. 53-64, 2011.

[16] Wong, J.T. \& Huang, S.H., Attention allocation patterns in naturalistic driving. Accident Analysis and Prevention, 58, pp. 140-147, 2013.

[17] Huang, S.H. \& Wong, J.T., A multinomial choice model approach for dynamic driver vision transitions. Accident Analysis and Prevention, 74, pp. 107-117, 2015.

[18] VTTI Data Warehouse, Online. http://forums.vtti.vt.edu. 2014.

[19] Pentland, A. \& Liu, A., Modeling and prediction of human behavior. Neural Computation, 11(1), pp. 229-242, 1999.

[20] Yeo, H., Skabardonis, A., Halkias, J., Colyar, J. \& Alexiadis, V., Over-saturated freeway flow algorithm for use in next generation simulation. Transportation Research Record: Journal of the Transportation Research Board, 2088, pp. 68-79, 2008.

[21] Yeo, H., Shladover, S., Krishnan, H. \& Skabardonis, A., Microscopic traffic simulation of vehicle-to-vehicle hazard alerts on freeway. Transportation Research Record: Journal of the Transportation Research Board, 2189, pp. 68-77, 2010. 